\title{
水资源综合利用专项规划评估体系构建及应用
}

\author{
再杨涛 $^{1}$ ，吕伟娅 ${ }^{2}$ ，袁校柠 ${ }^{3}$ \\ 1）中通服咨询设计研究院有限公司，江苏南京 $210019 ； 2$ ) 南京工业大学城市建设学院，江苏南京 211800;
}

3）南京地铁小镇开发建设集团有限公司，江苏南京 210018

摘 要: 水资源综合利用专项规划作为城市规划的组成部分，在指导绿色生态城区水系统建设方面发 挥着越来越重要的作用. 为科学评估水资源综合利用专项规划实施效果, 构建规划评估体系, 建立包含编 制内容、实施效果及保障机制的多维度的全过程评估指标体系. 基于多个水资源专项规划和中国南京市河 西新城绿色生态城区阶段性运营评估项目，确定水资源综合利用专项规划评估指标权重。以南京河西新城 水资源综合利用专项规划为例作实证研究，分析水资源专项规划文本的完整性及合理性; 通过实地勘查考 察河西新城建设进度，检测地表水水质等，明确专项规划实施效果，建立保障机制。采用偏差分析方法对 评估结果进行梳理，找出南京河西新城水资源综合利用专项存在的问题，并为专项规划修编提出建议. 规 划评估结果显示，水资源综合利用专项规划基本达到指导城市水资源综合利用系统建设的目标，水资源综 合利用系统建设在规划引领下，取得了一定成效; 构建的指标体系可多角度评估水资源综合利用专项规划 实施效果，可为其他地区的水资源专项规划编制提供借鉴.

关键词：海绵城市；绿色生态城区；水资源综合利用；规划评估；指标体系；实施效果；指标权重； 案例分析

中图分类号：TU984 文献标志码：A doi：10.3724/SP. J.1249.2021.04358

\section{Establishment and application of special plan evaluation system for comprehensive utilization of water resources}

\author{
RAN Yangtao ${ }^{1}$, LÜ Weiya ${ }^{2}$, and YUAN Xiaoning ${ }^{3}$ \\ 1) China Information Consulting \& Designing Institute Co. Ltd., Nanjing 210019, Jiangsu Province, P. R. China \\ 2) Urban Construction Institute, Nanjing University of Technology, Nanjing 211800, Jiangsu Province, P. R. China
}

3 ) Nanjing Metro Town Development and Construction Group Co. Ltd., Nanjing 210018, Jiangsu Province, P. R. China

\begin{abstract}
As an integral part of urban planning, the special plan for comprehensive utilization of water resources plays an increasingly important role in guiding the construction of water system in green ecological urban areas. In order to scientifically evaluate the implementation effect of the special plan for comprehensive utilization of water resources, this paper constructs a plan evaluation system, and establishes a multi-dimensional and whole process evaluation index system including the preparation content, implementation effect and guarantee mechanism. Based on a number of water resources special plan and the stage operation evaluation project of Nanjing Hexi New District Green Ecological City, the weights of of evaluation indices of water resources comprehensive utilization special planning are determined. Finally, taking the special plan for comprehensive utilization of water resources in Nanjing
\end{abstract}

Received: 2021-04-06; Accepted: 2021-04-26; Online (CNKI) : 2021-06-01

Foundation: National Natural Science Foundation of China (51078182)

Corresponding author: Professor LÜ Weiya. E-mail: njwater@ vip.163.com

Citation: RAN Yangtao, LÜ Weiya, YUAN Xiaoning. Establishment and application of special plan evaluation system for comprehensive utilization of water resources [J]. Journal of Shenzhen University Science and Engineering, 2021, 38(4) : 358-366. (in Chinese) 
Hexi New District as an example, this paper analyzes the integrity and rationality of the system, and inspects the construction progress of Hexi New District through field investigation, and detects the surface water quality within the plan scope, so as to clarify the implementation effect of the special plan and establish the guarantee mechanism. At the same time, the deviation analysis method is used in the planning evaluation to find the planning problems of the comprehensive utilization of water resources in Nanjing Hexi New District, and put forward suggestions for the revision of the special plan. According to the results of planning evaluation, the special planning of comprehensive utilization of water resources has basically achieved the goal of guiding the construction of urban water resources comprehensive utilization system. Under the guidance of the special plan, the construction of water resources comprehensive utilization system has achieved certain results. The index system constructed in this paper can evaluate the implementation effect of water resources comprehensive utilization special plan from multiple perspectives, and has a certain reference significance for the compilation of water resources special plan in other regions.

Key words: sponge city; green ecological city; comprehensive utilization of water resources; plan evaluation; index system; implementation effect; index weight; case analysis

在 2020 年第 75 届联合国大会一般性辩论上, 习近平总书记提出中国的二氧化碳排放将力争于 2030 年前达到峰值, 努力争取 2060 年前实现碳中 和. 为达成这一目标, 全面减少二氧化碳排放势在 必行. 人为因素导致的碳排放问题主要存在于工 业、交通及建筑 3 个行业. 根据预测，随着时间推 移, 我国工业和交通产生的碳排放比例将逐渐减 少，未来建筑行业碳排放占比可能达到 $50 \%$ 左 右 ${ }^{[1]}$. 目前减少建筑行业碳排放的重要途径是促使 传统建筑逐步走向 “绿色化”. 这种建筑的 “绿色 化” 进程, 已经由最初的建筑单体节能逐步发展为 绿色生态城区 ${ }^{[2]}$ 建设. GB/T 51255-2017 《绿色生 态城区评价标准 $\rangle^{[3]}$ 提出, 绿色生态城区是 “在空 间布局、基础设施、建筑、交通、产业配套等方 面，按照资源节约环境友好的要求进行规划、建 设、运营的城市开发区、功能区、新城区等”.

绿色生态城区建设要求以总体规划为引领, 编 制绿色生态系列专项规划, 包括绿色建筑、能源利 用和水资源综合利用等子专项规划 ${ }^{[4]}$. GB/T 51255-2017《绿色生态城区评价标准》明确要求, 绿色生态城区应在方案、规划阶段编制水资源综合 利用专项规划（以下简称 “水资源专项规划”). 随着绿色生态城区建设快速推进, 诸多城区均开展 了水资源综合利用专项规划编制工作. 因此, 如何 评价水资源专项规划实施的有效性成为当下研究的 重点. 本研究结合现有案例尝试对城区水资源综合 利用规划进行综合评估, 期望对纠正水资源专项规 划实施过程中的偏差, 为进一步提升水资源综合利 用效力提供一定的借鉴意义, 并对其他城区水资源 专项规划编制带来一定启发.

\section{1 专项规划评估内容及方法}

水资源专项规划指在绿色生态城区范围内, 在 城市总体规划的框架下, 以区域控制性详细规划为 依据, 在适宜于当地环境与资源条件的前提下, 将 供水、污水和雨水等统筹安排, 以达到高效、低 耗、节水、减排和生态目的的专项规划. 目前, 中 国的绿色生态城区发展已经从研究制定专项规划、 确定建设目标转人全面实施建设的关键期. 水资源 专项规划工作重点应从体系构建、技术研究转到落 地实施和跟踪效果上来 ${ }^{[5]}$.

\section{1 评估内容及方法}

规划评估内容主要包含: (1) 文本编制评估, 即对规划文本内容及表达的评估; (2) 规划效果评 估, 即考察规划内容落实程度和实施效果, 并与规 划目标进行比较; (3) 保障机制评估, 即对规划实 施过程的保障体系进行评估 ${ }^{[6-7]}$. 本研究尝试通过 构建评估指标体系的方法, 以中国南京市河西新城 区为案例, 从以上 3 个方面对城市水资源综合利用 规划进行系统性评估. 本研究的相关数据来自于对 南京河西新城区历年的建设资料的梳理, 同时进行 了必要的分析测试和实地调研.

\section{2 评估范围与时间}

南京河西新城区位于南京市主城的西片区, 坚 持“人文、宜居、智慧、绿色、集约” 的理念, 于 2012 年成功申报绿色建筑生态城区示范区, 并于 2013 年完成水资源专项规划编制, 规划重点区域为河西 新城南部地区和江心洲. 由于江心洲地区开发建设 进度较慢, 故本次选取规划面积约 $15 \mathrm{~km}^{2}$ 的河西 
新城南部地区进行评估. 时段上以河西新城区城市 水资源综合利用规划完成编制的 2013 年为起始年, 分析水资源专项规划编制状况，评估 2013-2017 年河西新城区城市水资源综合利用系统实施情况.

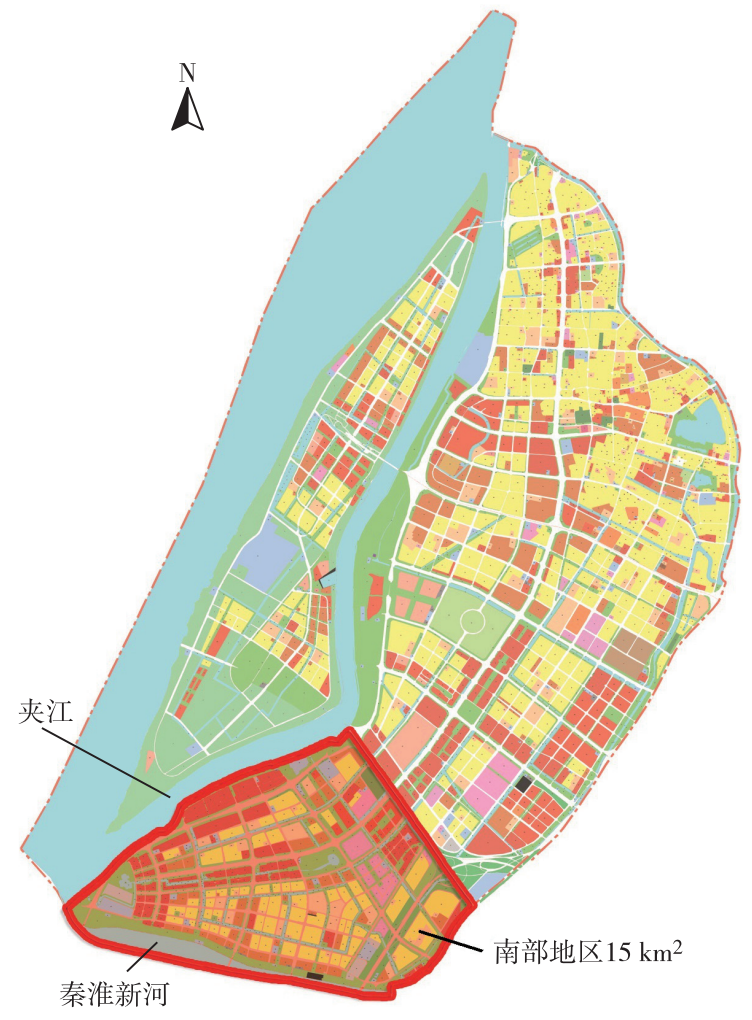

图 1 水资源专项规划评估范围

Fig. 1 Scope of water resources special plan assessment

\section{2 专项规划评估体系构建}

\section{1 评估体系建立原则}

水资源专项规划评估目的在于找出实施过程中 存在的问题及影响规划落实的原因，并提出相应的 调整意见和建议 ${ }^{[8]}$ 。评估体系指标选取时秉持精准 性、全面性和可量化原则，篮选合适的指标体系， 并量化相关指标，尽可能通过量化的数学模型，将 实施效果与规划文本进行比对，以期达到真实、有 效地反映水资源专项规划评估效果的目标 ${ }^{[9]}$.

1）精准性原则。选取有代表性的指标，采用 精准性原则，宁缺冊滥，旨在能够较为准确并完整 地反映水资源专项规划实施效果.

2）全面性原则. 水资源专项规划指标的选取 应兼顾城市水资源系统的各个重要方面, 选出的典 型指标应能较为完整的反映城市水资源系统的建设
效果, 避免缺失重要要素.

3) 可量化原则. 在建立水资源专项规划评估 体系过程中, 选择指标要素应力争可量化 ${ }^{[10]}$, 并 以此与水资源专项规划目标进行对比. 规划中的定 量指标（如再生水利用率等）可以量化操作，而定 性指标（如规划愿景阐述等）可以采取赋值的方法 量化.

\section{2 构建规划指标体系}

参照 GB/T 51255-2017 《绿色生态城区评价 标准》, 借鉴较为成熟的城市总体规划评估体

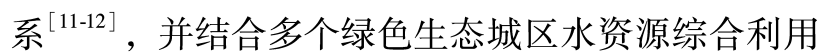
规划编制经验，本研究将水资源专项规划评估体系 分为 3 大维度共 37 项指标，见表 1 . 根据上述规划 评估体系，制作指标权重调查问卷，向江苏省从事 绿色生态城区研究的政府、事业单位、高校和设计 院等的从业人员发放. 以现场调研测试结果为依 据，结合问卷评分，确定各指标的权重.

\section{3 指标量化}

指标量化采取分级评估、客观判断评估及百分 比评估 3 种方法 ${ }^{[13]}$ ，见表 2. 参照 GB/T 51255一 2017《绿色生态城区评价标准》的条文内容或标准 值，对各项指标进行评分，总得分 50\% 64\% 的为 合格， $65 \% \sim 79 \%$ 的为良好， $80 \% \sim 100 \%$ 的为 优秀.

\section{3 专项规划编制成果评估}

以南京市南部新城区为例，根据规划评估体系 及指标权重，将规划文本内容及指标与实施结果进 行对比分析，得到河西新城区城市水资源综合利用 系统实施成效评估结果.

规划效果评估核心思路是将南京河西新城区水 资源专项规划实施效果与规划目标进行对比，检验 规划实施效果. 对规划编制文本采用定性判断，从 内在有效性及外在有效性两方面对专项规划进行分 级评估，衡量规划文本自身的合理性及完整性. 规 划实施效果评估则基于现场调研、考察和测试等对 可量化指标进行评估. 同时, 实施效果在很大程度 上依赖于政府行政干预、财政支持及社会协作，规 划保障机制是确保规划实施的重要环节 ${ }^{[14]}$. 因此, 通过对南京河西新城区行政文件检索及对政府和社 会相关人士的调研，分析保障机制的健全情况. 通 过以上定性判断及定量分析，明确南京河西新城区 水资源专项规划实施效果. 
表 1 水资源综合利用专项规划评估指标体系表

Table 1 Evaluation index system of special plan for comprehensive utilization of water resources

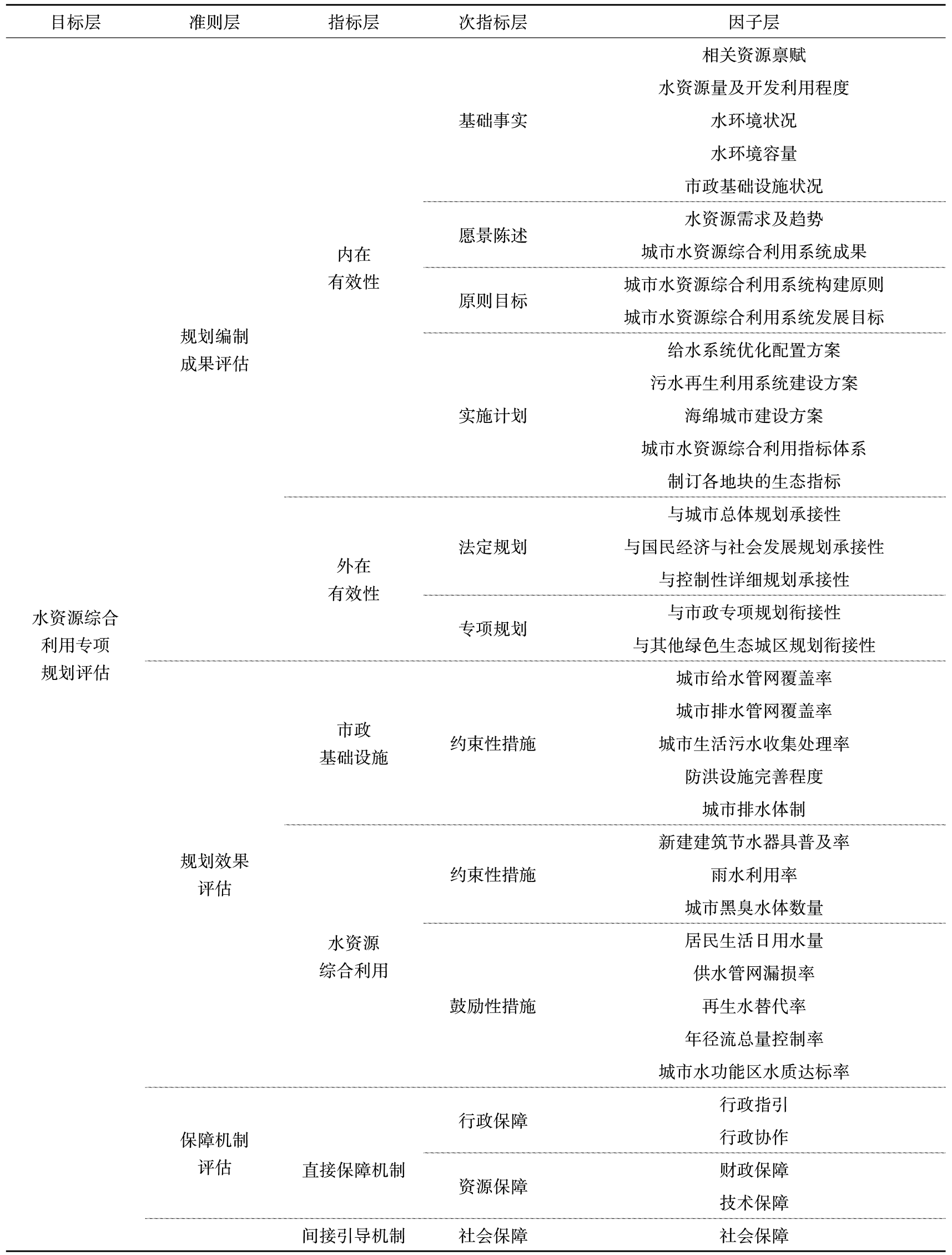


表 2 指标量化分析表

Table 2 The indices of quantitative analysis

\begin{tabular}{|c|c|c|c|}
\hline 序号 & 方 法 & 对 象 & 量化标准 \\
\hline 1 & 分级评估 & 无法定量分析指标 & $\begin{array}{l}\text { 根据文本是否提及、是否描述清晰, 或是否满足条件, 将指标分为 } 0 \text { 、 } \\
60 \% \text { 、 } 80 \% \text { 和 } 100 \%\end{array}$ \\
\hline 2 & 客观判断评估 & 无法定量分析指标 & 根据指标是否满足条件进行赋值, 满足得分为 $100 \%$, 不满足得分为 0 \\
\hline 3 & 百分比评估 & 可定量分析指标 & 按百分比进行考核, 即将指标完成状况与目标值进行对比确定其大小 \\
\hline
\end{tabular}

\section{1 规划编制成果内在有效性评估}

1）基础事实评估. 水资源综合利用规划文本 (以下简称 “规划文本”) 基础事实分析较为全面, 资源禀赋和市政基础设施状况描述清晰，得分为 100\%。规划文本在水资源量及水环境状况方面有 所涉及，但分析不够深人，得分为 $60 \%$ 。水环境容 量方面，规划无相关论述，得分为 0 .

2) 愿景陈述. 规划文本从多个角度提出了城 市水资源综合利用系统的需求，并预测了发展趋 势. 城市水资源综合利用系统成果方面，涵盖了给 水系统、雨水系统、污水和再生水系统，成果描述 详细的，二者均得分 $100 \%$.

3) 原则目标. 规划文本明确提出发展目标和 系统构建原则. 文本原则较为清晰, 目标较为明确 的，二者均得分 $100 \%$.

4) 实施计划. 规划文本在海绵城市建设方案 方面有所欠缺，文本中仅描述了适宜于河西新城区 的各种绿色雨水基础设施，规划措施不够具体，该 指标得分为 $60 \%$. 其余的建设方案均论述清晰, 指 标得分均为 $100 \%$.

综上所述，水资源专项规划内在有效性方面， 论述较为清晰, 文本框架较为合理, 但在基础设施 方面，对于水资源开发利用程度及水环境状况方面 尚需加强论述，对于水环境容量方面仍需进行深度 分析; 实施计划方面要加强海绵城市建设方案论 述, 制定具体方案, 同时需增加防洪排涝方面分析.

\section{2 规划编制成果外在有效性评估}

水资源专项规划文本一般根据法定规划及其他 各类专项规划进行编制，将自来水供水系统、污水 再生系统及海绵城市建设等统筹安排. 水资源专项 规划与相关规划关系见图 2.

1）法定规划. 规划对 《南京市城市总体规划》 中相关内容进行了一定的解读，与城市总体规划承 接性指标得分为 $60 \%$. 规划文本是在《南京河西 新城区南部地区控制性详细规划》相关要求和规划 原则限制下完成，与控制性详细规划衔接性指标得 分为 $100 \%$ 。但水资源综合利用规划未与国民经济

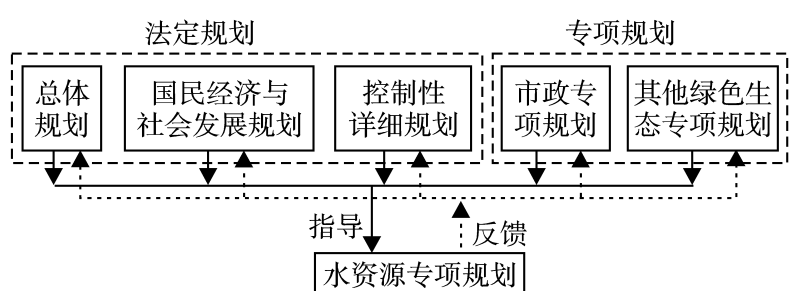

图 2 水资源专项规划及相关规划关系

Fig. 2 Water resources plan and related plans

与社会发展规划进行承接，该指标得分为 0 .

2）相关专项规划. 规划文本参考当地制定的 市政专项规划，设置市政基础设施，但少部分市政 基础设施未落实，该指标得分为 $80 \%$ 。若规划文本 基本未考虑与绿色交通、能源综合利用等其他绿色 生态城区专项规划衔接，该指标得分为 0 .

综上所述，水资源专项规划外在有效性方面， 能够有效承接城市总体规划与控制性详细规划，但 对于国民经济与社会发展规划没有涉及，对于其他 相关绿色生态城区专项规划也没有进行有效衔接.

\section{3 水资源专项规划效果评估}

1）市政基础设施. 河西新城南部地区市政基 础设施建设状况良好, 供水管网及排水管网完全满 足已建项目建设需求，见图 3 和图 4. 供水管网覆 盖率、污水管网覆盖率、生活污水收集处理率及排

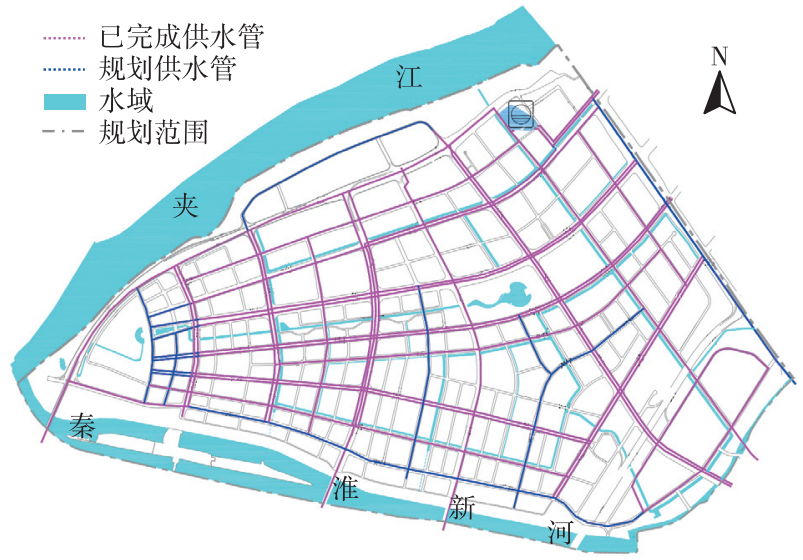

图 3 供水管网建设进度

Fig. 3 Construction progress of water supply network 


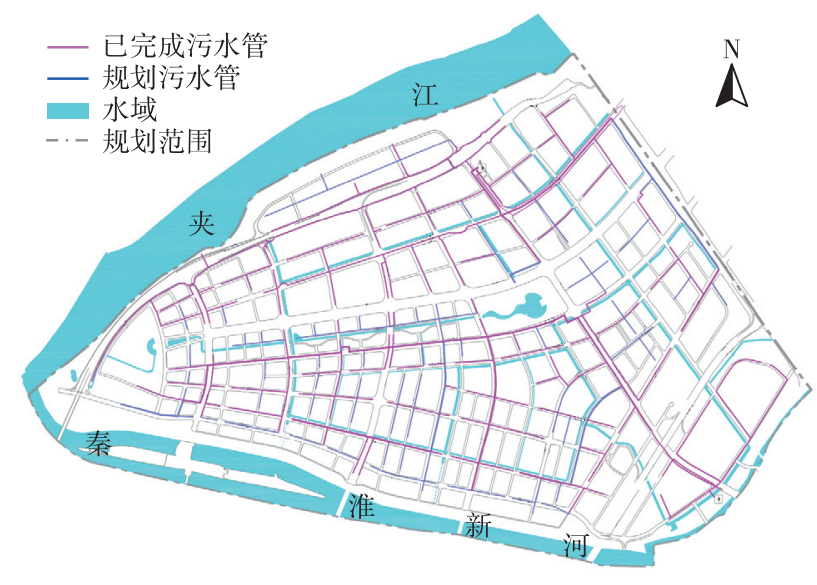

图 4 污水管网建设进度

Fig. 4 Construction progress of sewage pipe network

水体制得分为 $100 \%$; 防洪排涝设施建设基本完成 (最南部除外)，该指标得分为 $80 \%$.

2) 水资源综合利用. 河西新城新建建筑均采 用节水器具, 且河西新城南部地区重点示范项目中 均建设了雨水回用系统, 平均雨水利用率为 $3.81 \%$ ，见表 3 .

\section{表 3 雨水回用系统建设情况}

Table 3 Construction of rainwater recycling system

\begin{tabular}{|c|c|c|c|}
\hline 序号 & 项目名称 & 雨水利用率 $/ \%$ & 建设进度 \\
\hline 1 & 国际风情街 & 1.38 & 已建 \\
\hline 2 & 南部市政综合体 & 1.81 & 在建 \\
\hline 3 & 正荣集团 C、D 地块 & 3.28 & 在建 \\
\hline 4 & 正荣集团 $\mathrm{E}$ 地块 & 25.93 & 在建 \\
\hline 5 & $\begin{array}{c}\text { 市纪委、监察局新建 } \\
\text { 配套附属用房 }\end{array}$ & 6.36 & 已建 \\
\hline 6 & 河西儿童医院 & 3.82 & 已建 \\
\hline 7 & 南京海峡城 $\mathrm{C}$ 地块 & 3.74 & 已建 \\
\hline 8 & 南京海峡城 E 地块 & 5.16 & 已建 \\
\hline 9 & 五矿住宅及社区中心 & 3.27 & 已建 \\
\hline 10 & 五矿幼儿园 & 21.58 & 已建 \\
\hline 11 & 南京外国语学校河西分校 & 10.34 & 已建 \\
\hline
\end{tabular}

2013 年 1 月一-2016 年 6 月, 南京市环保局对 区域内主要水系 (秦淮新河和南河) 水质进行连续监 测. 其中，区域内主要水系的水质指标包括化学需 氧量 (chemical oxygen demand, COD)、氨氮和总磷 基本可达到 $\mathrm{V}$ 类及以上要求（具体结果请扫描论文 末页右下角二维码查看图 S1一图 S3), 无黑臭水
体. 鉴于南京市自来水公司并未单独计量河西新城 区管网漏损状况, 再生水系统还未投入使用. 由此 可知, 水资源综合利用方面, 供水管网漏损率指标得 分为 0 , 再生水替代率指标得分为 0 , 其余指标均 达到目标，得分为 $100 \%$.

综上所述, 城市水资源综合利用方面, 绝大多 数指标达到水资源专项规划要求, 少部分指标如管 网漏损率和再生水替代率有待进一步完善.

\section{4 保障机制评估}

1）行政指引方面. 河西新城区城市水资源建 设过程中各相关系统均有规范及标准进行参照, 其 中更多地依赖于国家颁布的各种标准及规范, 地方 颁布的标准及规范较少，该指标得分为 $60 \%$.

2）行政协作方面. 河西新城区管委会专门成 立了领导小组, 由分管副市长牵头承担重要问题的 抉择和审批工作, 同时还成立了专家组, 提供咨 询, 但建设过程中的多依赖建设部门指导, 其余部 门参与较少，该指标得分为 $80 \%$.

3）财政保障方面. 住建厅及财政厅颁布了一 系列办法, 如 《关于建立南京河西新城区绿色生态 城区工作领导小组的通知》, 同时, 河西新城区管 委会根据省级相关规定, 制定了专项引导资金管理 办法，该指标得分为 $100 \%$.

4）技术保障方面. 河西新城区从 3 方面完善 绿色生态城区水资源综合利用系统的技术保障措 施, 包括技术导则、专项规划技术支撑团队和绿色 建筑咨询单位, 但在具体项目建设时未进行全面指 导，该指标得分为 $80 \%$.

5) 社会保障方面. 城市水资源综合利用系统 建设中, 企业有一定的参与, 但未做到及时与群众 进行深人交流、协作, 社会保障较弱, 该指标得分 为 $60 \%$.

\section{4 规划评估结果分析}

\section{1 规划评估结果}

从规划评估结果来看, 水资源专项规划最终得 分为 79.96\%, 基本达到了指导城市水资源综合利 用系统建设的目标 (表 4). 水资源综合利用系统建 设在规划引领下, 取得了一定成效.

\section{2 规划评估分析}

通过偏差分析对评估结果进行梳理, 结果见表 5. 由表 5 可知, 南京河西新城区水资源专项规划 文本编制基本符合要求, 编制成果偏差 $16.19 \%$, 主 
表 4 水资源专项规划评估结果

Table 4 Evaluation results of water resources plan

\begin{tabular}{|c|c|c|c|c|c|c|c|}
\hline 准则层 & 指标层 & 次标层 & 因子层 & 权重/\% & 得分 $/ \%$ & 评估得分 $/ \%$ & 指标偏差 $/ \%$ \\
\hline \multirow{19}{*}{$\begin{array}{l}\text { 规划编制 } \\
\text { 成果评估 }\end{array}$} & \multirow{14}{*}{$\begin{array}{c}\text { 内在 } \\
\text { 有效性 }\end{array}$} & \multirow{5}{*}{ 基础事实 } & 相关资源禀赋 & 0.81 & 100 & 0.81 & 0 \\
\hline & & & 水资源量及开发利用程度 & 0.96 & 60 & 0.58 & 40 \\
\hline & & & 水环境状况 & 0.90 & 60 & 0.54 & 40 \\
\hline & & & 水环境容量 & 1.05 & 0 & 0.00 & 100 \\
\hline & & & 市政基础设施状况 & 1.10 & 100 & 1.10 & 0 \\
\hline & & \multirow{2}{*}{ 愿景陈述 } & 水资源需求及趋势 & 1.44 & 100 & 1.44 & 0 \\
\hline & & & 城市水资源综合利用系统成果 & 1.69 & 100 & 1.69 & 0 \\
\hline & & \multirow{2}{*}{ 原则目标 } & 城市水资源综合利用系统构建原则 & 1.83 & 100 & 1.83 & 0 \\
\hline & & & 城市水资源综合利用系统发展目标 & 2.55 & 100 & 2.55 & 0 \\
\hline & & \multirow{5}{*}{ 实施计划 } & 给水系统优化配置方案 & 1.36 & 100 & 1.36 & 0 \\
\hline & & & 污水再生回用系统建设方案 & 1.43 & 100 & 1.43 & 0 \\
\hline & & & 海绵城市建设方案 & 2.13 & 60 & 1.28 & 40 \\
\hline & & & 城市水资源综合利用指标体系 & 1.17 & 100 & 1.17 & 0 \\
\hline & & & 制订各地块的生态指标 & 1.23 & 100 & 1.23 & 0 \\
\hline & \multirow{5}{*}{$\begin{array}{c}\text { 外在 } \\
\text { 有效性 }\end{array}$} & \multirow{3}{*}{ 法定规划 } & 与城市总体规划承接性 & 2.95 & 80 & 2.36 & 20 \\
\hline & & & 与国民经济与社会发展规划承接性 & 2.03 & 0 & 0.00 & 100 \\
\hline & & & 与控制性详细规划承接性 & 4.31 & 100 & 4.31 & 0 \\
\hline & & \multirow{2}{*}{ 专项规划 } & 与市政专项规划衔接性 & 4.77 & 80 & 3.82 & 20 \\
\hline & & & 与其他绿色生态城区规划衔接性 & 3.56 & 0 & 0.00 & 100 \\
\hline \multirow{13}{*}{$\begin{array}{l}\text { 规划 } \\
\text { 效果 } \\
\text { 评估 }\end{array}$} & \multirow{5}{*}{$\begin{array}{c}\text { 市政 } \\
\text { 基础设施 }\end{array}$} & \multirow{5}{*}{ 约束性措施 } & 城市给水管网覆盖率 & 3.77 & 100 & 3.77 & 0 \\
\hline & & & 城市排水管网覆盖率 & 3.77 & 100 & 3.77 & 0 \\
\hline & & & 城市生活污水收集处理率 & 3.14 & 100 & 3.14 & 0 \\
\hline & & & 防洪设施完善程度 & 3.30 & 80 & 2.64 & 20 \\
\hline & & & 城市排水体制 & 3.29 & 100 & 3.29 & 0 \\
\hline & \multirow{8}{*}{$\begin{array}{c}\text { 水资源 } \\
\text { 综合利用 }\end{array}$} & \multirow{3}{*}{ 约束性措施 } & 新建建筑节水器具普及率 & 2.59 & 100 & 2.59 & 0 \\
\hline & & & 雨水利用率 & 3.25 & 100 & 3.25 & 0 \\
\hline & & & 城市黑臭水体个数 & 4.53 & 100 & 4.53 & 0 \\
\hline & & \multirow{5}{*}{ 鼓励性措施 } & 居民生活日用水量 & 0.82 & 100 & 0.82 & 0 \\
\hline & & & 供水管网漏损率 & 1.54 & 0 & 0.00 & 100 \\
\hline & & & 再生水替代率 & 1.22 & 0 & 0.00 & 100 \\
\hline & & & 年径流总量控制率 & 1.82 & 100 & 1.82 & 0 \\
\hline & & & 城市水功能区水质达标率 & 1.51 & 80 & 1.21 & 20 \\
\hline \multirow{5}{*}{$\begin{array}{l}\text { 保障 } \\
\text { 机制 } \\
\text { 评估 }\end{array}$} & \multirow{4}{*}{$\begin{array}{c}\text { 直接 } \\
\text { 保障机制 }\end{array}$} & \multirow{2}{*}{ 行政保障 } & 行政指引 & 5.66 & 60 & 3.40 & 40 \\
\hline & & & 行政协作 & 4.90 & 80 & 3.92 & 20 \\
\hline & & \multirow{2}{*}{ 资源保障 } & 财政保障 & 4.48 & 100 & 4.48 & 0 \\
\hline & & & 技术保障 & 4.17 & 80 & 3.34 & 20 \\
\hline & 引导机制 & 社会保障 & 社会保障 & 8.97 & 60 & 5.38 & 40 \\
\hline & & 合计 & & 100 & 100 & 79.96 & - \\
\hline
\end{tabular}


要原因在于河西新城水资源专项规划编制时间较 早，近些年政府及学术界对于海绵城市、水环境容 量等内容愈加重视, 故河西新城水资源专项规划部 分内容与当前城市水资源系统需求产生偏差. 实施 效果偏差为 $8.10 \%$, 说明水资源系统建设过程紧跟 城市水资源系统发展趋势, 规划实施效果较好. 保 障机制偏差为 $2.80 \%$ ，说明河西管委会建立了较有 效的运营管理模式, 保障了水资源专项规划的实施.

以保障机制评估为例, 直接保障机制偏差最 小, 说明河西新城建立起完善的行政保障机制及资 源保障机制, 间接引导机制偏差为 $40 \%$, 说明河西 新城城市水资源系统建设过多依赖于政府引导, 水 资源系统建设需要让群众及企业的参与进来.

表 5 规划评估指标偏差 ${ }^{1)}$

Table 5 The Index deviation of plan evaluation

\begin{tabular}{|c|c|c|c|}
\hline 准则层 & 指标层 & $\begin{array}{l}\text { 次指 } \\
\text { 标层 }\end{array}$ & $\begin{array}{l}\text { 指标 } \\
\text { 偏差/\% }\end{array}$ \\
\hline \multirow{6}{*}{$\begin{array}{l}\text { 规划编制 } \\
\text { 成果评估 } \\
(16.19 \%)\end{array}$} & \multirow{4}{*}{$\begin{array}{c}\text { 内在有效性 } \\
(12.60 \%)\end{array}$} & 基础事实 & 37.24 \\
\hline & & 愿景陈述 & 0.00 \\
\hline & & 原则及目标 & 0.00 \\
\hline & & 实施计划 & 14.66 \\
\hline & \multirow{2}{*}{$\begin{array}{c}\text { 外在有效性 } \\
(21.75 \%)\end{array}$} & 法定规划 & 40.70 \\
\hline & & 专项规划 & 23.63 \\
\hline \multirow{3}{*}{$\begin{array}{l}\text { 实施效果 } \\
\text { 评估 } \\
(8.10 \%)\end{array}$} & $\begin{array}{c}\text { 市政基础设施 } \\
(3.82 \%)\end{array}$ & 约束措施 & 3.82 \\
\hline & \multirow{2}{*}{$\begin{array}{c}\text { 水资源综合利用 } \\
(12.37 \%)\end{array}$} & 约束措施 & 0.00 \\
\hline & & 鼓励措施 & 30.94 \\
\hline \multirow{3}{*}{$\begin{array}{c}\text { 保障机制 } \\
\text { 评估 } \\
(2.80 \%)\end{array}$} & \multirow{2}{*}{$\begin{array}{c}\text { 直接保障机制 } \\
(0.00 \%)\end{array}$} & 行政保障 & 0.00 \\
\hline & & 资源保障 & 0.00 \\
\hline & $\begin{array}{c}\text { 间接引导机制 } \\
(40.00 \%)\end{array}$ & 社会保障 & 40.00 \\
\hline
\end{tabular}

1) 括号内数字为指标偏差

\section{5 规划修编建议}

1) 加强基础事实的论述. 通过对水资源专项 规划评估可知, 规划对于水环境容量及水环境状况 等论述不够深人, 宜结合当地资源禀赋, 深人分析 当地的水环境容量, 加强水环境状况等论述.

2) 深化海绵城市方案. 海绵城市建设已经成 为城市重要的基础设施构成之一 ${ }^{[15]}$, 河西新城区
水资源专项规划由于编制时间问题，对于海绵城市 建设方案论述不够细致, 没有给出较全面的规划措 施, 宜从防洪排涝及绿色雨水基础设施设置规模等 方面深化海绵城市建设方案.

3) 衔接更多的城市规划. 水资源专项规划与 相关规划衔接性不够强, 仅仅深人分析了控制性详 细规划、市政规划内的相关内容, 对于总规、国民 经济发展规划等相关规划未进行深人分析. 建议补 充水资源专项规划与更多城市规划的衔接内容.

4) 进一步丰富保障机制内容. 水资源专项规 划虽涉及保障机制, 但比较笼统, 缺乏落地性. 建 议将保障机制细分为行政保障、财政保障、技术保 障等方面, 并进行细化, 丰富保障机制内容.

\section{结 语}

本研究提出水资源综合利用专项规划评估的方 法与内容, 建立规划评估指标体系, 并以南京河西 新城区为例, 开展了水资源综合利用专项规划评估 的实证研究. 通过对规划的编制成果、实施效果及 保障机制的评估, 分析规划编制的科学性、适宜性 和有效性, 以期达到促进城市水资源综合利用规划 不断发展完善的目标.

基金项目：国家自然科学基金资助项目（51078182）

作者简介: 再杨涛 (1991-), 中通服咨询设计研究院有限公司工 程师. 研究方向: 绿色建筑和海绵城市. E-mail: ranyt @ foxmail.com

引文: 再杨涛, 吕伟娅, 袁校柠. 水资源综合利用专项规划评 估体系构建及应用 $[\mathrm{J}]$. 深圳大学学报理工版, 2021，38 (4) : 358-366

\section{参考文献 / References :}

[ 1 ] 王有为. 谈 “碳” ——碳达峰与碳中和愿景下的中国 建筑节能工作思考 $[\mathrm{J}]$. 建筑节能, 2021, 49(1)：19.

WANG Youwei. China's building energy efficiency efforts to peaking carbon dioxide emissions and achieving carbon neutrality $[\mathrm{J}]$. Building Energy Efficiency, 2021, 49 (1): 1-9. ( in Chinese)

[2] 乔伟峰, 吴 菊, 戈大专, 等. 快速城市化地区土地 利用规划管控建设用地扩张成效评估一以南京市为 例 $[\mathrm{J}]$. 地理研究, 2019, 38(11): 2666-2680.

QIAO Weifeng, WU Ju, GE Dazhuan, et al. Evaluating the controlling effectiveness of land-use planning on construction land expansion under the rapid urbanization: a case study of Nanjing city $[\mathrm{J}]$. Geographical Research, 
2019, 38(11): 2666-2680. (in Chinese)

[ 3 ] GB/T 51255-2017 绿色生态城区评价标准 [S]. GB/T 51255-2017 Assessment standard for green ecodistrict $[\mathrm{S}]$. (in Chinese)

[ 4 ] 吕伟娅, 管益龙, 张金戈. 绿色生态城区海绵城市建 设规划设计思路探讨 $[\mathrm{J}]$. 中国园林，2015，31(6)： 16-20.

LÜ Weiya, GUAN Yilong, ZHANG Jin'ge. Discussion of the design ideas of sponge city planning in " green ecodistrict” planning $[\mathrm{J}]$. Chinese Landscape Architecture, 2015, 31(6): 16-20. (in Chinese)

[5]杜海龙, 李 迅, 李 冰. 中外典型绿色生态城区评 价标准系统化比较研究 $[\mathrm{J}]$. 城市发展研究, 2020 , $27(11)$ : 57-65.

DU Hailong, LI Xun, LI Bing. Systematic comparative study on evaluation standards of typical green ecological urban districts $[\mathrm{J}]$. Urban Development Studies, 2020, $27(11)$ : 57-65. (in Chinese)

[6]杨 秀, 余龄敏, 赵秀峰, 等. 乡村振兴背景下的乡 村发展潜力评估、分类与规划引导 $[\mathrm{J}]$. 规划师， 2019, 35(19) : 62-67.

YANG Xiu, YU Lingmin, ZHAO Xiufeng, et al. Evaluation, classification, and planning guidance of rural development potential in rural revitalization $[\mathrm{J}]$. Planners, 2019, 35(19) : 62-67. (in Chinese)

[ 7 ] 张满银. 省级区域规划实施评估方法和机制探究 $[\mathrm{J}]$. 经济地理, 2020, 40(4): 75-82, 95.

ZHANG Manyin. The methods and mechanisms of the implementation evaluation of provincial regional planning [J] . Economic Geography, 2020, 40(4) : 75-82, 95. (in Chinese)

[8] 杨丝雨, 宋云婷, 王丹丹. 吉林省国土空间规划实施 评估探索 $[\mathrm{J}]$. 规划师，2020，36(S2): 17-22.

YANG Siyu, SONG Yunting, WANG Dandan. Assessment of land and spatial planning implementation in Jilin province $[\mathrm{J}]$. Planners, 2020, 36 ( S2 ) : 17-22. (in Chinese)

[ 9 ] 刘 建, 龚小强, 任心欣, 等. 深圳市海绵城市的建 设与创新 $[J]$. 深圳大学学报理工版, 2020, 37(4)： 334-346.

LIU Jian, GONG Xiaoqiang, REN Xinxin, et al. Sponge city construction and innovation in Shenzhen $[\mathrm{J}]$. Journal of Shenzhen University Science and Engineering, 2020, 37 (4) : 334-346. (in Chinese)

[10] 杨亚红, 间俊江, 蔚 阳, 等. 校园低影响开发渗蓄 性能及成因模拟分析 $[\mathrm{J}]$. 深圳大学学报理工版, 2020, 37(4) : 362-371.

YANG Yahong, YAN Junjiang, YU Yang, et al. Simula- tion analysis of infiltration performance and cause of low impact development in university campus $[\mathrm{J}]$. Journal of Shenzhen University Science and Engineering, 2020, 37 (4) : 362-371. (in Chinese)

[11] 刘 曼, 王国恩. 以人为本理念下的城市总体规划实 施评估框架与体系 $[J]$. 规划师，2019(20)：26-31.

LIU Man, WANG Guo'en. Human oriented urban master plan implementation evaluation [ J ]. Planners, 2019 (20) : 26-31. (in Chinese)

[12] 张月金. 城市总体规划实施评估思路探讨一以南宁 为例 $[\mathrm{J}]$. 规划师, $2017,33(9)$ ：113-119.

ZHANG Yuejin. Evaluation model of master planning implementation: nanning example $[\mathrm{J}]$. Planners, 2017, 33(9) : 113-119. (in Chinese)

[13］彭世瑾，胡爱兵，史敬华，等. 基于深圳典型片区海 绵城市监测评估的思考 $[\mathrm{J}]$. 深圳大学学报理工版, 2021, 38(1) : 1-9.

PENG Shijin, HU Aibing, SHI Jinghua. Reflection on the sponge city monitoring and evaluation in Shenzhen $[\mathrm{J}]$. Journal of Shenzhen University Science and Engineering, 2021, 38(1) : 1-9. (in Chinese)

[14] 黄建欣, 宋 彦, 高文秀, 等. 纽约包容性城市规划 经验对我国的借鉴 $[\mathrm{J}]$. 城市发展研究, 2019, 26 (6) : 45-51, 86 .

HUANG Jianxin, SONG Yan, GAO Wenxiu, et al. Learning from the experience of inclusive urban planning in New York city [J] . Urban Development Studies, 2019, 26(6) : 45-51, 86. (in Chinese)

[15] 王志杰, 周 平, 刘川昆, 等. 海绵城市潜力评估方 法及地下排水系统 $[\mathrm{J}]$. 哈尔滨工业大学学报, 2018, $50(03)$ : 118-127.

WANG Zhijie, ZHOU Ping, LIU Chuankun, et al. A potential evaluating methods of sponge city and on the underground drainage system $[\mathrm{J}]$. Journal of Harbin Institute of Technology, 2018, 50 (03): 118-127. (in Chinese)

【中文责编：晨 兮; 英文责编：之 聿】 